\title{
FORMAS FARMACÊUTICAS SEMISSÓLIDAS A BASE DE PAPAÍNA - AVALIAÇÃO PRELIMINAR DA ESTABILIDADE, CONTAMINAÇÃO MICROBIOLÓGICA E ATIVIDADE ENZIMÁTICA
}

\author{
SEMI-SOLID PHARMACEUTICAL FORMS BASED ON PAPAIN - PRELIMINARY \\ EVALUATION OF STABILITY, MICROBIOLOGICAL CONTAMINATION AND \\ ENZYMATIC ACTIVITY
}

\author{
Júlio Cézar BORELLA ${ }^{1,2}$; Juliana Coelho Lopes TEIXEIRA ${ }^{1}$; Robison Leandro \\ Aparecido PUGA²; Marise C. Bastos STEVENATO²
}

1 - Laboratório de Manipulação Farmacêutica da Secretaria Municipal da Saúde de Ribeirão Preto

2 - Curso de Ciências Farmacêuticas, Universidade de Ribeirão Preto (UNAERP)

Autor para correspondência: jborella@unaerp.br

\section{RESUMO:}

Géis (usando carbômero) e cremes (usando base autoemulsionante aniônica), contendo $2 \%(p / p), 6 \%(p / p)$ e 10\% (p/p) de papaína, são utilizados para fins de cicatrização e desbridamento de ferimentos. Com estas formulações, armazenadas em dois ambientes (5-10 ํㅡ e 30-35 으), durante 4 meses, foram realizadas análises $(\mathrm{pH}$, análise organoléptica, espalhabilidade, análise microbiológica, teste de centrifugação e atividade enzimática) para avaliar estabilidade, contaminação por micro-organismos e ação proteolítica. Os resultados mostraram que, para ambas as formas farmacêuticas, em temperaturas mais elevadas, houve maior rapidez na perda da atividade enzimática. Géis com altas concentrações de papaína $(10 \%$ p/p) são inviáveis, pois apresentaram espalhabilidade anormais. Os cremes com papaína, em todas as concentrações, apresentaram separação de fases pelo teste de centrifugação, mostrando instabilidade termodinâmica. Os cremes (6\% p/p e 10\% p/p) apresentaram decréscimo intenso e rápido (entre 24 horas a 1 semana após preparo) da atividade enzimática, inviabilizando seu uso por períodos prolongados. Resultados de $\mathrm{pH}$ e contaminação microbiológica não foram determinantes para reprovação das formulações. Sendo assim, o gel a $2 \%(p / p)$ foi a única formulação que não apresentou problemas críticos de estabilidade e perda de atividade enzimática, se for mantido entre $5-10 \stackrel{\circ}{\circ}$.

Palavras chaves: Papaína, Produção de medicamentos, Controle da qualidade, Análise microbiológica, Estabilidade enzimática.

\section{ABSTRACTS:}

Gels (using carbomer) and creams (using anionic self-emulsifying wax) containing $2 \%$ (w/w), $6 \%(\mathrm{w} / \mathrm{w})$ and $10 \%(\mathrm{w} / \mathrm{w})$ are used for wound healing and debridement purposes. Analysis $(\mathrm{pH}$, organoleptic analysis, spreadability, microbiological analysis, centrifugation test and enzymatic activity) were carried with theses formulations to evaluate stability, contamination by microorganisms and proteolytic action, in two storage environments (5-10 ${ }^{\circ} \mathrm{C}$ and $30-35$ $\left.{ }^{\circ} \mathrm{C}\right)$, for 4 months. The results showed that, for both forms evaluated, at higher temperatures, there was a greater speed in relation to the loss of the enzymatic activity. Gels with high concentrations of papain $(10 \% \mathrm{w} / \mathrm{w})$ are not feasible, because they have abnormal spreadability characteristics. The creams with papain, in all concentrations, showed phase 
separation by centrifugation test, showing thermodynamic instability. The creams $(6 \% \mathrm{w} / \mathrm{w}$ and $10 \% \mathrm{w} / \mathrm{w}$ ) showed intense and fast (between 24 hours to 1 week after prepared) decrease of the enzymatic activity, making it unfeasible for prolonged periods. Results of $\mathrm{pH}$ variations and microbiological contamination were not determinant for rejection of the formulations. Thus, gel $2 \%(\mathrm{w} / \mathrm{w})$ was the only formulation that did not present critical stability problems and loss of enzyme activity, if maintained between $5-10{ }^{\circ} \mathrm{C}$.

Keywords: Papain, Production of products, Quality control, Microbiological analysis, Enzyme stability.

\section{INTRODUÇÃO}

No âmbito farmacêutico, desde os tempos de Galeno, há uma procura incessante pela melhor formulação para uso terapêutico dos ativos medicinais. Este empenho visa dar mais eficácia ao tratamento e comodidade ao paciente (SILVA et al., 2010; VIANA et al., 2006). Deste modo, com a evolução das técnicas de manipulação, surgiram várias formas farmacêuticas que possibilitaram garantir estas condições. Algumas delas foram desenvolvidas com o objetivo de veicular ativos para uso tópico, como são os casos das preparações semissólidas (géis e cremes). Os primeiros são constituídos por suspensões de partículas (dispersões coloidais), como grandes moléculas orgânicas, interpenetradas por um líquido (ANSEL, POPOVICK; ALLEN JR., 2000). Os segundos são sistemas emulsionados, resultantes de uma fase interna formada por gotículas de um líquido, distribuídas em um veículo, no qual é imiscível (fase externa), empregando-se para sua estabilização um sistema tensoativo (FRIEDRICH et al., 2007).

A papaína é uma enzima (cisteína protease) presente no látex do mamoeiro (Carica papaya). Devido à sua natureza proteica, a atividade enzimática está diretamente relacionada com a manutenção da estrutura molecular, incluindo a do seu sítio catalítico (BORELLA; STEVANATO, 2015). Vários fatores são conhecidos e competem para anular ou preservar sua atividade enzimática. $\mathrm{O}$ aumento da temperatura, $\mathrm{pH}$ com valores muito baixos ou elevados, presença de agentes oxidantes e umidade são alguns fatores que diminuem a atividade da papaína, enquanto a adição de agentes redutores moderados (cisteína, EDTA) mantém o grupo sulfidrila livre no sítio catalítico, o qual ativa e preserva a ação da enzima (MIURA, 2012).

Embora nos EUA seja proibida sua utilização terapêutica, através de legislações da Food and Drug Administration (2008), ela é usada em vários outros países, inclusive no Brasil, para uso tópico, com o objetivo, entre outros, de cicatrização e desbridamento de feridas. As alegações quanto a sua eficácia terapêutica parecem estar evidenciadas pelos diversos estudos que as atestam (BRITO JR.; FERREIRA, 2015; RIBEIRO et al., 2015; 
RODRIGUES et al., 2015; LEITE et al., 2012; LOPES et al., 2008; FERREIRA et al., 2005). No entanto, a proibição nos EUA se refere à possibilidade de sensibilidade alérgica ao látex. Contudo, situação como esta, parece ser rara no Brasil (ASSOCIAÇÃO BRASILEIRA DE ENFERMAGEM EM DERMATOLOGIA, 2008).

Para fins de cicatrização e desbridamento de feridas, pode-se fazer uso da papaína de diversas formas, desde uso do látex "in natura" (GURUNGA; SKALKO-BASNET, 2008; STARLEY et al.1999), passando por soluções da enzima e até sua incorporação em formas farmacêuticas mais complexas, como é o caso de géis e cremes (SOUZA et al., 2017; RIBEIRO et al., 2015).

Com relação aos géis contendo papaína, observa-se que um dos agentes gelificantes mais comumente utilizados são carbômeros, derivados de ácidos carboxivinílicos (Carbopo ${ }^{\circledR}$ ), resultando em hidrogéis orgânicos monofásicos. Pela sua natureza aniônica, este tipo de agente é dependente de pH e são estáveis em pH próximo ao neutro, como também é a condição ideal para a papaína, em relação à sua atividade enzimática (CORREA et al., 2005).

Por outro lado, as bases cremosas são, por natureza, sistemas termodinamicamente instáveis (emulsões) e consequências desta condição podem ser percebidas em produtos deste tipo, como a separação de fases e instabilidade do ativo incorporado. Existem vários tipos de bases cremosas que são utilizadas na área farmacêutica. Elas podem possuir caráter não iônico ou iônico (catiônico e aniônico) (ZANIN et al., 2001).

A escolha do melhor tipo é muitas vezes dependente do ativo que será incorporado, na tentativa de melhor estabiliza-lo e deixa-lo disponível para utilização, mas não há padronização das formulações, em relação a estes temas. Observa-se, no entanto, que cremes utilizando bases autoemulsionantes não iônicas, contendo álcoois graxos de cadeia longa, como os álcoois cetílico, estearílico e cetoestearílico (Crodabase CR-2 ${ }^{\circledR}$ ) são amplamente utilizadas na manipulação de produtos farmacêuticos, por possuírem menor toxicidade, exibirem menores problemas de compatibilidade com outros materiais e serem menos sensíveis à mudança de pH e adição de eletrólitos (ZANIN et al., 2001).

Desta forma, além da baixa qualidade dos insumos utilizados nas formulações contendo papaína (BORELLA, PÁDUA; STEVANATO, 2015), outros problemas relacionados à eficácia destas preparações devem envolver fatores como a manutenção da atividade enzimática e estabilidade da própria formulação, que podem estar relacionados com o tempo e temperatura de armazenagem (BORELLA et al., 2016).

Avaliações preliminares da estabilidade para preparações semissólidas mais rotineiramente usadas incluem características organolépticas, $\mathrm{pH}$, contaminação microbiológica, espalhabilidade, centrifugação, entre outras. Para avaliação da atividade 
enzimática, técnicas imunológicas e enzimáticas de doseamento são empregadas. As primeiras são baseadas na interação da papaína com um anticorpo e as segundas, mais comuns, são dependentes da hidrólise quantitativa de um substrato proteico com utilização da papaína (PINTO et al., 2007).

Neste sentido, na tentativa de contribuir para melhor entendimento e utilização destes tipos de formulações, este trabalho contempla estudos relativos às formulações de géis e cremes, contendo papaína, tendo por objetivo avaliar preliminarmente o comportamento relativo à estabilidade (análises organolépticas, $\mathrm{pH}$, espalhabilidade e centrifugação), contaminação microbiológica e atividade enzimática (método de coagulação do leite) de preparações farmacêuticas semissólidas (géis e cremes) contendo papaína (2\% $\mathrm{p} / \mathrm{p}, 6 \% \mathrm{p} / \mathrm{p}$ e $10 \% \mathrm{p} / \mathrm{p})$ frente à estocagem em diferentes condições de temperatura (5-10 $\stackrel{\circ}{ } \mathrm{C}$ - geladeira e $30-35^{\circ} \mathrm{C}$ - estufa).

\section{MATERIAL E MÉTODOS}

\subsection{Insumos e preparo das formulações}

Para o desenvolvimento das análises foram produzidos géis e cremes, conforme formulações descritas na TABELA 1.

TABELA 1. Formulações dos géis e cremes de papaína

\begin{tabular}{lcccc}
\hline Gel & Testemunha & $2 \%(\mathrm{p} / \mathrm{p})$ & $6 \%(\mathrm{p} / \mathrm{p})$ & $10 \%(\mathrm{p} / \mathrm{p})$ \\
\hline Papaína & 0,000 & 2,000 & 6,000 & 10,000 \\
Carbopol Ultrex $^{\circledR}$ & 0,880 & 0,880 & 0,880 & 0,880 \\
EDTA dissódico & 0,004 & 0,004 & 0,004 & 0,004 \\
Metilparabeno & 0,180 & 0,180 & 0,180 & 0,180 \\
Etilparabeno & 0,020 & 0,020 & 0,020 & 0,020 \\
Propilenoglicol & 15,000 & 15,000 & 15,000 & 15,000 \\
NaOH (pH $~ 7,0)$ & $\mathrm{qs}$ & $\mathrm{qs}$ & $\mathrm{qs}$ & $\mathrm{qs}$ \\
Água pur. qsp & 100,000 & 100,000 & 100,000 & 100,000 \\
\hline Creme & Testemunha & $2 \%(\mathrm{p} / \mathrm{p})$ & $6 \%(\mathrm{p} / \mathrm{p})$ & $10 \%(\mathrm{p} / \mathrm{p})$ \\
\hline Papaína & 0,000 & 2,000 & 6,000 & 10,000 \\
Crodabase CR2 & 22,500 & 22,500 & 22,500 & 22,500 \\
EDTA dissódico & 0,100 & 0,100 & 0,100 & 0,100 \\
Metilparabeno & 0,050 & 0,050 & 0,050 & 0,050 \\
Etilparabeno & 0,150 & 0,150 & 0,150 & 0,150 \\
Propilenoglicol & 5,000 & 5,000 & 5,000 & 5,000 \\
Água pur. qsp & 100,000 & 100,000 & 100,000 & 100,000 \\
\hline
\end{tabular}


Os géis contendo papaína foram preparados a partir dos seguintes insumos, previamente qualificados para uso farmacêutico (análise do certificado de qualidade expedido pelo fornecedor e testes de controle de qualidade segundo Farmacopeia Brasileira 5 $5^{\text {a }}$ edição): Carbômero (Carbopol Ultrez 10 ${ }^{\circledR}$ ) Fagron lote 15010686A; Metilparabeno Dinâmica lote 57416; Etilparabeno Fagron lote 20120828\#3; EDTA dissódico Fagron lote 15063527B; Propilenoglicol Fagron lote 14073478A; Hidróxido de sódio Allchemistry lote ALL057356; Papaína 6000 UI/mg Allchemistry lote ALL056679 e Água purificada Laboratório de Manipulação Farmacêutica lote AP.10.16.

A técnica de preparo consistiu em deixar o agente gelificante em contato com água purificada por uma hora. Posteriormente, com agitação constante, foi acrescentada a solução aquosa de hidróxido de sódio para formação do gel. Os conservantes foram solubilizados em propilenoglicol e foram adicionados ao gel. Por fim, houve a adição da papaína, previamente solubilizada em parte da água purificada. Todas as etapas de produção foram realizadas com agitação constante do sistema. O gel foi então envasado em potes plásticos brancos leitosos, fechados e rotulados.

Os cremes contendo papaína foram preparados a partir dos seguintes insumos, previamente qualificados pelos certificados de análises expedidos pelos fornecedores e por análises de controle de qualidade realizadas conforme Farmacopeia Brasileira 5a edição: Cera autoemulsionante não iônica (Crodabase $\mathrm{CR}^{\circledR}$ ) Allchemistry lote ALL 061567; Metilparabeno Dinâmica lote 57416; Etilparabeno Fagron lote 20120828\#3; EDTA dissódico Fagron lote 15063527B; Propilenoglicol Fagron lote 14073478A; Papaína 6000 UI/mg Allchemistry lote ALL056679 e Água purificada Laboratório de Manipulação Farmacêutica lote AP.10.16.

Os cremes foram produzidos aquecendo-se a cera autoemulsionante a $70 \stackrel{\circ}{ } \mathrm{C}$, até sua fusão. A água purificada também foi aquecida até temperatura próxima àquela da cera e então foi solubilizado o EDTA dissódico. Também neste momento, a fase aquosa foi dispersa na fase oleosa, com constante agitação. Após diminuição da temperatura do sistema (por volta de $40 \stackrel{\circ}{\circ}$ ), foi adicionado, ainda com agitação, o propilenoglicol, no qual foram dissolvidos os conservantes e, por fim, houve adição da papaína, previamente solubilizada em parte da água purificada. Todas as etapas de produção foram realizadas com agitação constante do sistema. O creme foi envasado em potes plásticos brancos leitosos, fechados e rotulados. 


\subsection{Ambiente de estocagem}

Os géis e cremes de papaína foram estocados em dois diferentes ambientes, considerando a temperatura entre $5-10{ }^{\circ} \mathrm{C}$ (em geladeira, marca Elber modelo $\mathrm{Re} 280$ ) e entre $30-35^{\circ} \mathrm{C}$ (em estufa, marca Marconi modelo MA032/4).

\subsection{Testes realizados}

As formulações produzidas foram submetidas a diversas análises, que foram realizadas com três amostras $(n=3)$ para cada condição de estocagem e cada uma das análises foram realizadas em triplicada. Foi utilizada para apresentação dos resultados, a média aritimética dos resultados destas análises. Os resultados das análises de $\mathrm{pH}$, consistência por espalhabilidade e atividade enzimática foram submetidos à análise de variância (ANOVA) e posterior teste de comparação múltipla de Tukey-Kramer, ao nível de $5 \%$ de probabilidade. As análises organolépticas, de $\mathrm{pH}$, espalhabilidade, centrifugação e atividade enzimática, de início, foram realizadas no dia do preparo das formulações e um dia após a manipulação. Depois houve realização de análises semanais, até o primeiro mês após preparo das formulações. Em seguida, foram realizadas análises mensais até o quarto mês após o início do experimento. As análises de contaminação microbiológica foram realizadas no início e no final do período de estocagem.

\subsection{Análise organoléptica}

As análises organolépticas tiveram avaliação comparativa entre as amostras e foram observadas a homogeneidade (aspecto), coloração e odor das preparações, conforme preconizado por DUARTE (2016), NICOLETTI (2015), MIURA (2012) e PINTO (2005).

\subsection{Determinação do pH}

Foi realizada a metodologia descrita na Farmacopeia Brasileira $5^{\text {a }}$ edição (BRASIL, 2010), empregando aparelho de marca Orion modelo 420A. A aferição do aparelho foi realizada com as leituras de soluções tampão $(\mathrm{pH}=4,0$ e $\mathrm{pH}=7,0)$ imediatamente antes da determinação do $\mathrm{pH}$ da solução-teste. Preparou-se solução-teste a 10\% (p/p) com as 
amostras, usando-se água purificada como solvente e procedeu-se a medida do pH (ISAAC et al., 2008).

\subsection{Espalhabilidade}

O teste de espalhabilidade foi realizado segundo Knorst (1991), com modificações. Um anel metálico com $15 \mathrm{~mm}$ de diâmetro e $5 \mathrm{~mm}$ de espessura foi usado como molde para amostra e foi colocado no centro de uma placa-suporte de vidro. Sob esta placa posicionou-se uma folha de papel milimetrado. A amostra foi introduzida no orifício do anel e a superfície foi nivelada com espátula. Após, o anel foi cuidadosamente retirado. Sobre a amostra foi colocada uma placa de vidro de peso pré-determinado. Após 1 minuto foi calculada a superfície ocupada pela amostra, pela medida do diâmetro em duas posições opostas, com o cálculo do diâmetro médio. Este procedimento foi repetido acrescentandose mais pesos sobre a placa-suporte, em intervalos de 1 minuto, registrando-se a cada adição, a superfície abrangida, até a obtenção de valores constantes. Por este método é possível representar a espalhabilidade da forma farmacêutica através do cálculo da espalhabilidade máxima (ponto no qual a adição de massa não provoca alterações significativas nos valores das áreas). Para determinação destes valores, foram utilizados testes de análise de variância, seguidos do teste de Bonferroni $(p<0,05)$, para comparações múltiplas entre as médias dos diferentes pontos de espalhabilidade. O esforço-limite corresponde à massa adicionada no valor de espalhabilidade máxima (MILAN et al., 2007; BORGHETTI; KNORST, 2006). A apresentação dos resultados considera a relação entre as áreas de espalhabilidade máxima e o esforço-limite.

\subsection{Análise microbiológica}

As técnicas realizadas visaram a contagem de microrganismos viáveis e foram utilizados os meios de cultura TSA (avaliação do crescimento de bactérias) e Sabouraud (avaliação do crescimento de fungos). As amostras foram submetidas ao tratamento com solução neutralizante, para inativação dos conservantes e possibilitar homogeneização das amostras. Os isolamentos de coliformes totais e fecais, Pseudomonas aeruginosa e Staphylococcus aureus foram realizados usando os meios de cultura MacConkey, Cetrimida e Vogel-Johnson. As formulações contendo papaína foram solubilizadas e diluídas na proporção de 1:10; 1:100 e 1:1000, antes da semeadura nos meios de cultura, 
e previamente incubadas para recuperação dos microrganismos pesquisados (BOUCHACRA; OHARA, 2003). Demais provas bioquímicas não foram realizadas, pois a análise desenvolvida foi para a utilização de formulações farmacêuticas para uso tópico.

\subsection{Teste de centrifugação}

Este ensaio visa produzir estresse na formulação pelo aumento da força da gravidade. Essa situação força o aumento da mobilidade das partículas e prevê possíveis instabilidades (BONTORIM, 2009). As formulações foram submetidas ao ensaio preliminar de estabilidade por centrifugação, usando centrífuga Fanen 206 - Baby I, com velocidade de 6000 rpm, durante 10 minutos (ISAAC et al., 2008).

\subsection{Atividade enzimática}

O método de coagulação do leite se fundamenta na alteração das características deste substrato proteico durante período de incubação. Por este método, $1 \mathrm{~g}$ das amostras dos géis e cremes foi disperso em $10 \mathrm{~g}$ de solução de ácido acético $0,01 \%$ (p/p) e esta mistura adicionada a $10 \mathrm{~mL}$ de leite $(2,5 \mathrm{~g}$ do leite em pó desnatado em $100 \mathrm{~g}$ de água), previamente aquecido, em banho de água, até a temperatura de $50{ }^{\circ} \mathrm{C}$. Esta mistura foi agitada até o primeiro sinal de formação de coágulos, observados com lupa (ampliação de $4 \mathrm{x}$ ), contra fundo escuro. O tempo decorrido para a formação do coágulo, a partir da adição da amostra ao leite, foi usado para o cálculo da atividade enzimática, expressa em unidade de potência de coagulação do leite por grama da formulação com papaína (Upe) (MAHECHA, RODRIGUEZ; CORREA, 2011):

$$
\text { Upe }=1000(E . t)-1
$$

Onde: E: massa (mg) de solução necessária para precipitar $10 \mathrm{~mL}$ do substrato (leite) no tempo t (min)

\section{RESULTADOS E DISCUSSÃO}

\subsection{Análises organolépticas}

Depois de realizados os ensaios descritos e compilação dos dados, pode-se 
observar que os géis testemunhas se apresentaram homogêneos, incolores e inodoros durante todo o período de armazenagem, em ambas as temperaturas. Géis de papaína a $2 \%(\mathrm{p} / \mathrm{p})$, conservados em geladeira, mantiveram-se homogêneos, incolores e com odor característico, durante todo o período de avaliação. Os géis a 6\% (p/p) e 10\% (p/p), mantidos em geladeira, também se mantiveram homogêneos e com odor característico. No entanto, suas colorações, desde o início da estocagem, eram levemente amareladas, para as preparações a 6\% (p/p) e amareladas para as formulações a 10\% (p/p), e se mantiveram sem alterações, até o final do período de avaliação. Esta coloração, nestas formulações de maior concentração, se deve à própria cor da papaína, que se apresenta com tonalidade amarelada (BORELLA, PÁDUA; STEVANATO, 2015).

As alterações de coloração e odor mais intensas foram detectadas nos géis que foram conservados em estufa. Géis a $2 \%(p / p)$ de papaína mostraram cor levemente amarelada, após 24 horas de estocagem. A coloração se intensificou, tornando-se amarelada, após duas semanas de armazenagem. Os géis a 6\% (p/p) de papaína sofreram intensificação da cor a partir da $2^{a}$ semana de armazenagem (amarelado). Géis a 10\% (p/p) se apresentaram fortemente amarelados, a partir da $3^{a}$ semana de estocagem. Associados a estas alterações, o odor característico de papaína também foi se intensificando nestes mesmos momentos para os géis a $6 \%(\mathrm{p} / \mathrm{p})$ e $10 \%(\mathrm{p} / \mathrm{p})$ de papaína.

As formulações cremosas estocadas em geladeira tiveram comportamento inalterado durante o período de avaliação. Mantiveram-se homogêneas, brancas e com odor característico. Estes mesmos resultados foram observados para as amostras testemunhas, nos dois ambientes de estocagem. Aquelas amostras estocadas na estufa, mostraram alteração de cor (levemente amareladas) para formulação a $2 \%$ (p/p), a partir do $3^{\circ}$ mês de estocagem. Preparações cremosas a 6\% (p/p) e 10\% (p/p) com papaína apresentaram alterações de cor a partir da $2^{\mathrm{a}}$ semana de estocagem (levemente amareladas), intensificando-se a partir do $3^{\circ}$ mês de estocagem em diante (amareladas). Não houve alterações perceptíveis no aspecto (homogêneas) e odor (característico).

Estes resultados evidenciam que a estocagem realizada em temperaturas elevadas pode produzir efeitos indesejáveis à formulação, com alteração na coloração e odor, com possíveis consequências para atividade farmacológica. Miura (2012) e Pinto (2005) citam que alterações deste tipo estão associadas à degradação da papaína. Sendo assim, características como estas podem ser utilizadas para averiguar, de forma preliminar, as condições de armazenagem que estes produtos foram submetidos e possíveis consequências negativas quanto às suas eficácias terapêuticas. 


\section{$3.2 \mathrm{pH}$}

Os resultados das leituras de $\mathrm{pH}$ nas formulações preparadas não apresentaram grandes variações, quer sejam para os géis, quer sejam para os cremes, nos dois ambientes de estocagem, durante todo período avaliado. Fato semelhante é citado por Miura (2012), que enfatiza a manutenção dos valores de $\mathrm{pH}$ em estudos de estabilidade acelerada em géis de papaína ( $2 \%$ p/p e $4 \%$ p/p, usando Carbopol 940), durante 2 meses de estudos.

Os géis a $2 \%(p / p), 6 \%(p / p)$ e $10 \%(p / p)$ de papaína apresentaram $\mathrm{pH}$ que variaram entre 5,0 a $5,5 . \mathrm{O}$ pH dos cremes $2 \%(\mathrm{p} / \mathrm{p}), 6 \%(\mathrm{p} / \mathrm{p})$ e $10 \%(\mathrm{p} / \mathrm{p})$ variou entre 5,5 a 6,0 . Os valores encontrados, no transcorrer do experimento, não mostraram ser estatisticamente diferentes entre si, pelo teste de Tukey, ao nível de $5 \%$ de probabilidade. Desta forma, os resultados indicaram que este tipo de análise não seria útil, durante o período de estocagem, para monitorização de alterações químicas que poderiam estar ocorrendo nas formulações.

\subsection{Espalhabilidade}

Os resultados das análises de espalhabilidade mostraram ser estatisticamente iguais (Teste de Tukey, ao nível de $5 \%$ de probabilidade) para cada tipo de formulação (gel ou creme) e para cada concentração avaliada ( $2 \%$ p/p, $6 \%$ p/p e 10\% p/p), nos dois ambientes de estocagem, durante todo o período de estocagem.

Para os géis a $2 \%(\mathrm{p} / \mathrm{p})$ e a $6 \%(\mathrm{p} / \mathrm{p})$, além da testemunha, foram observados valores de espalhabilidade na ordem de $0,020 \mathrm{~mm}^{2} / \mathrm{g}$ (área/esforço limite). Alteração neste resultado foi estatisticamente observada para as formulações dos géis a $10 \%(p / p)$, nas duas condições de estocagem, onde foi encontrada espalhabilidade de $0,090 \mathrm{~mm}^{2} / \mathrm{g}$. Esta situação leva a interpretação de que formulações usando a quantidade especificada de Carbopol Ultrez $10^{\circledR}(0,88 \% \mathrm{p} / \mathrm{p})$, associada à grande concentração de papaína $(10 \% \mathrm{p} / \mathrm{p})$, não dão condições para a manutenção da estrutura coloidal e perdem suas características, alterando a espalhabilidade. Problemas deste tipo podem ser resolvidos com adição de maior quantidade do agente gelificante (DUARTE, 2016). Neste sentido, este mesmo pesquisador desenvolveu e avaliou estabilidade e atividade enzimática de formulações de géis de papaína a $10 \%$ (p/p) e concluiu que com o uso Carbopol $940^{\circledR}(2 \%$ p/p) resultaram preparações estáveis.

O valor médio de $0,040 \mathrm{~mm}^{2} / \mathrm{g}$ foi calculado para expressar a espalhabilidade para 
todas formulações cremosas avaliadas, independentemente das concentrações de papaína e temperatura de armazenagem. Deste modo, observou-se que, para este tipo de formulação cremosa, a massa de papaína empregada e a temperatura durante a estocagem não foram determinantes para alteração do parâmetro analisado. Diferentemente destes resultados, em análises realizadas com formulações cremosas (Polawax $^{\circledR}$ - Cera autoemulsionante não iônica) sem adição de ativos, Zanin et al. (2016) relataram que houve sensíveis modificações quando foram armazenadas em ambientes com temperaturas em torno de $50^{\circ} \mathrm{C}$, inclusive com forte alteração da espalhabilidade.

\subsection{Contaminação microbiológica}

A avaliação microbiológica das amostras foi realizada utilizando-se o meio de cultura TSA e o meio de cultura Sabouraud, no início e ao final do período de estocagem. As placas apresentaram baixo crescimento de colônias, sem ultrapassar os limites permitidos pela legislação (BRASIL, 2010). Estes meios foram também encubados com amostras na diluição de 1:100 e 1:1000 e, nestas condições, não houve crescimento bacteriano ou fúngico. Presença de coliformes totais e fecais, Staphylococcus aureus e Pseudomonas aeruginosa foi avaliada, respectivamente, nos ágares MacConkey, VogelJohnson e Cetrimida, onde os resultados foram negativos. Desse modo, as amostras avaliadas estão dentro dos limites estabelecidos, no início até o final do período de estocagem avaliado, mesmo naqueles ambientes com temperaturas mais elevadas. Neste sentido, ressalta-se que Ferreira et al. (2008) e Payne et al. (2008) citam que a própria papaína apresenta atividade antimicrobiana, além de propriedade cicatrizante e desbridante.

\subsection{Ensaio preliminar de centrifugação}

Observou-se que, para as amostras de creme a 2\% (p/p), 6\% (p/p) e 10\% (p/p) de papaína, houve separação de fases após realização da centrifugação, independentemente do ambiente de estocagem. As testemunhas não apresentaram este resultado, mostrandose perfeitamente homogêneas, após a realização do teste. Isto parece evidenciar que a formulação cremosa, com adição de papaína, é termodinamicamente instável e deverá ser reformulada para alterar esta condição.

Os géis avaliados não apresentaram qualquer alteração, após teste de centrifugação, exceto aqueles na concentração a 10\% (p/p), onde se observou separação de fases. Este 
resultado coaduna com aquele citado anteriormente para espalhabilidade, para as mesmas amostras, evidenciando instabilidade na estrutura coloidal da preparação. Esta situação demonstra a inviabilidade do uso desta formulação para fins terapêuticos, com a quantidade de agente gelificante especificada e deverá ser reformulada para adequação.

\subsection{Atividade enzimática}

Nas FIGURAS 1 a 4 estão apresentados os comportamentos das formulações contendo papaína, em relação à atividade enzimática durante o tempo de estocagem. As formulações testemunhas, para géis e cremes, não foram inseridas nestas figuras, pois apresentaram atividade enzimática nula (zero Upe), durante todo o período analisado, independentemente da temperatura no ambiente de estocagem.

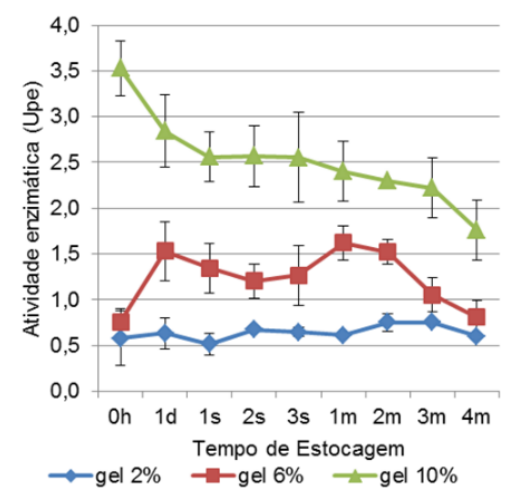

Legenda: $\mathrm{h}$ = hora; $\mathrm{d}=$ dia; $\mathrm{s}=$ semana; $\mathrm{m}=$ mês; barra de erros refere-se ao desvio padrão da média

FIGURA 1. Variação da atividade enzimática das formulações dos géis de papaína no período de estocagem em geladeira (5-10 oC)

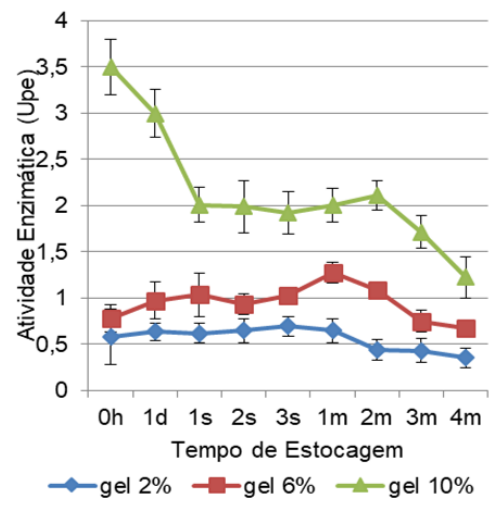

Legenda: $\mathrm{h}$ = hora; $\mathrm{d}=$ dia; $\mathrm{s}=$ semana; $\mathrm{m}$ = mês; barra de erros refere-se ao desvio padrão da média 
FIGURA 2. Variação da atividade enzimática das formulações dos géis de papaína no período de estocagem em estufa (30-35 oC)

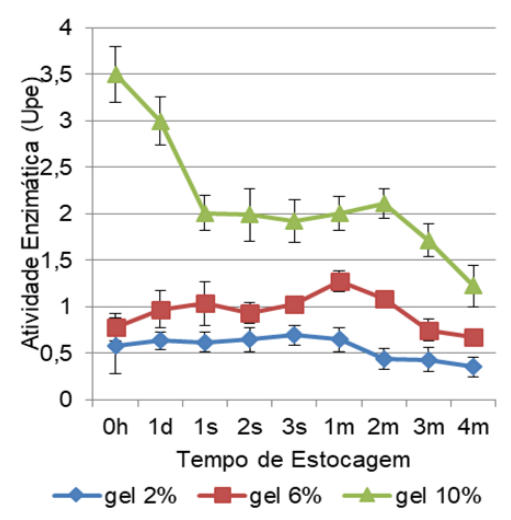

Legenda: $\mathrm{h}=$ hora; $\mathrm{d}=$ dia; $\mathrm{s}=$ semana; $\mathrm{m}=$ mês;

barra de erros refere-se ao desvio padrão da média

FIGURA 3. Variação da atividade enzimática das formulações dos cremes de papaína no período de estocagem em geladeira (5-10 oC)

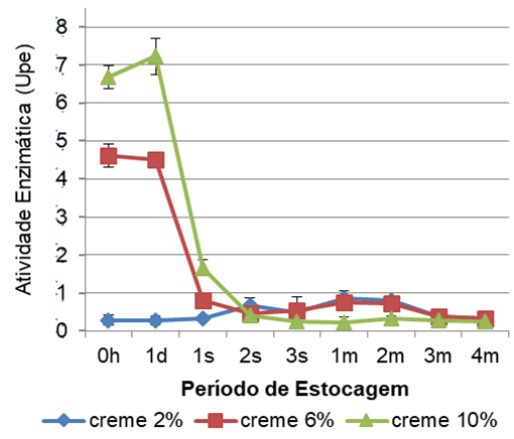

Legenda: $\mathrm{h}=$ hora; $\mathrm{d}=$ dia; $\mathrm{s}=$ semana; $\mathrm{m}=$ mês;

barra de erros refere-se ao desvio padrão da média

FIGURA 4. Variação da atividade enzimática das formulações dos cremes de papaína no período de estocagem em estufa (30-35 oC)

Com relação aos resultados obtidos da atividade enzimática das amostras, observou-se que ela decresce mais rapidamente se a estocagem for realizada em ambientes com temperaturas mais elevadas $\left(30-35^{\circ} \mathrm{C}\right)$, quando comparadas com as atividades das amostras estocadas em temperaturas menores $\left(5-10{ }^{\circ} \mathrm{C}\right)$, quer seja para a forma farmacêutica de gel ou creme. Isto reafirma dados da literatura que definem o ambiente refrigerado como condição ideal de estocagem para estes produtos (DUARTE, 
2016; NICOLETTI, 2015; MIURA, 2012; PINTO, 2005).

Os resultados em relação às atividades enzimáticas iniciais (tempo de estocagem $=0 \mathrm{~h}$ ), tanto para géis quanto para cremes, não apresentaram valores proporcionais em relação ao aumento da concentração de papaína usada na formulação. Desta forma, não é real concluir que, para uma dada forma farmacêutica contendo $6 \%(\mathrm{p} / \mathrm{p})$ de papaína, seja três vezes mais potente em sua ação, que a formulação a $2 \%$ (p/p). Observou-se que, na comparação dos géis, esta potência de ação é estatisticamente igual, enquanto para cremes, estocados em geladeira, a potência para as preparações de $6 \%(\mathrm{p} / \mathrm{p})$ é superior a três vezes (15,5 vezes maior). As preparações a 10\% (p/p), tanto para géis quanto para cremes, sempre apresentaram suas atividades enzimáticas iniciais superiores às demais formulações, embora também em desproporção com as atividades apresentadas por estas mesmas preparações.

Comparando-se as atividades enzimáticas dos géis e cremes com as mesmas concentrações de papaína, observou-se que os cremes, inicialmente, apresentam maiores valores, exceto a preparação a $2 \%(p / p)$, que apresentou a metade da atividade enzimática em relação ao gel. Tais variações sugerem que os componentes das formulações devam estar influenciando as atividades enzimáticas destes produtos.

No entanto, estes valores superiores se alteraram conforme o tempo de estocagem se prolongou e esta condição se deteriorou rapidamente. Isto parece mostrar que as formulações na forma de géis têm maiores condições de retardar a queda da atividade enzimática da papaína. Neste aspecto, ressalta-se a drástica perda de atividade enzimática observada pelos cremes contendo 6\% (p/p) e 10\% (p/p) de papaína, estocados na estufa e na geladeira. Para estes, o período de 1 semana e 2 semanas de estocagem foi suficiente para que ocorresse decréscimo de $82,5 \%$ e $93,7 \%$, respectivamente, de suas atividades enzimáticas inicialmente detectadas. Este quadro se acentua para aquelas formulações estocadas em estufa, onde se observa semelhante decréscimo da atividade enzimática, porém com somente 24 horas de estocagem. Desta forma, analisando estes dados, há um comprometimento da eficácia destas formulações se utilizadas após maiores tempos de estocagem.

O drástico decaimento da atividade enzimática das preparações emulsionadas contendo papaína também foi descrito por Pinto et al. (2011), onde relataram a diminuição de $90 \%$ da atividade enzimática em emulsões contendo papaína, armazenadas a $40^{\circ} \mathrm{C}$, no período de 90 dias.

Todas estas informações são importantes para assegurar a eficácia do tratamento 
com uso de preparações contendo papaína. Neste sentido, salienta-se que é comum no comércio de manipulação farmacêutica, o uso de prazos de validade de até quatro meses para estes produtos. Nota-se que para cremes a $6 \%(\mathrm{p} / \mathrm{p})$ e $10 \%(\mathrm{p} / \mathrm{p})$, a atividade enzimática é quase nula após 1 ou 2 semanas de estocagem em ambientes refrigerados. Isto inviabiliza, a médio e longo prazo, a eficácia destes produtos que seriam utilizados na limpeza de curativos (desbridamento). Deste modo, é importante que as farmácias de manipulação, que formulem preparações cremosas de papaína análogas às que foram testadas, orientem os pacientes em relação ao uso imediato da preparação, para que a ação desbridante seja atingida. Também para os géis a $10 \%(p / p)$, se observou o decaimento da atividade enzimática, conforme o tempo de estocagem, mas esta não ocorreu na mesma velocidade apresentada pelos cremes.

Os géis a $6 \%(\mathrm{p} / \mathrm{p})$ tiveram desempenho peculiar. Aqueles armazenados em geladeira, incialmente (tempo de estocagem $=0$ h) tiveram atividade enzimática semelhante estatisticamente àqueles géis a 2\% (p/p) (0,76 Upe), armazenados nas mesmas condições. Um dia após preparação, a atividade enzimática da formulação dobrou (1,53 Upe) e manteve-se neste nível até o $2^{\circ}$ mês de estocagem, quando entrou em queda. Este mesmo perfil havia sido detectado por Pinto et al. (2011), em preparações com papaína modificada e Borella et al. (2016), em estudos com soluções aquosas de papaína com adição de adjuvantes farmacotécnicos. Este comportamento pode ser explicado pela gradual ativação dos sítios catalíticos presentes em porções da enzima, a partir da preparação da formulação.

O gel a $2 \%(p / p)$ foi a formulação que apresentou maior estabilidade da atividade enzimática durante o período analisado. As preparações armazenadas em geladeira ou estufa apresentaram estatisticamente as mesmas atividades enzimáticas, até o segundo mês de estocagem, quando aquelas estocadas em estufa entraram em queda em relação ao seu poder proteolítico. As preparações mantidas na geladeira conservaram estatisticamente a mesma atividade até o quarto mês de estocagem.

\section{CONCLUSÕES}

Através da análise e discussão dos resultados apresentados, podemos concluir que:

- A contaminação microbiológica que foi detectada em todas as amostras, nos dois ambientes de estocagem, durante todo o período analisado estava dentro dos limites especificados pela legislação, garantindo segurança microbiológica na utilização destas 
formulações.

- A avaliação do pH, durante o período de estocagem, não representou parâmetro eficiente para indicar alterações químicas que possam estar ocorrendo nestas preparações.

- Caracteres organolépticos, como a cor e odor, podem ser utilizados, de forma preliminar nas análises, para indicativo de boas condições de estocagem destas preparações.

- Testes de estabilidade preliminar, por centrifugação, mostraram que, independentemente da temperatura de estocagem, todas as preparações cremosas contendo papaína são termodinamicamente instáveis e devem ser reformuladas. Os géis a $10 \%(p / p)$ também exibiram separação de fases, mostrando instabilidade provocada pelo desequilíbrio das proporções de agente gelificante (carbômero) e papaína. Este fato foi reforçado pela alteração da espalhabilidade que este tipo de formulação apresentou.

- Temperaturas mais elevadas de estocagem são prejudiciais à manutenção da atividade enzimática destas preparações (géis e cremes), principalmente para aquelas de maior concentração (6\% p/p; 10\% p/p).

- Os cremes com maiores concentrações de papaína (6\% p/p e 10\% p/p), inicialmente apresentaram maiores atividades enzimáticas que os géis nas mesmas concentrações, porém esta condição se deteriora rapidamente, com 1 e 2 semanas após preparo, estocados em geladeira, ou com 1 dia, se estocados em estufa. Isto inviabiliza o emprego destas preparações por períodos prolongados, após sua preparação.

- Géis a 2\% p/p de papaína apresentaram resultados dentro da normalidade em relação aos parâmetros analisados, quando armazenados em geladeira, resultando em formulação que apresentou bons parâmetros de estabilidade e atividade enzimática.

\section{REFERÊNCIAS}

ANSEL, H.C.; POPOVICH, N.G.; ALLEN JR, L.V. Farmacotécnica: formas farmacêuticas \& sistemas de liberação de fármacos. 6a. ed. São Paulo: Editorial Premier, 2000. 568p.

BRITO JR, L.C.; FERREIRA, P.L. Cicatrização de feridas contaminadas tratadas com papaína. Med. (Ribeirão Preto). 48(2):168-174, 2015.

BORELLA J.C.; STEVANATO, M.C.B. Análise sazonal da produção e da atividade enzimática de látex fresco coletado de frutos de plantas femininas e hermafroditas de mamão 
(Carica papaya L.). Rev. Bras. Plantas Med. 17(4, supl 3):1112-1117, 2015.

BORELLA, J.C.; PÁDUA, M.; STEVANATO, M.C.B. Estudo comparativo para avaliação da qualidade de amostras de papaína comercializadas por empresas fornecedoras de insumos farmacêuticos do estado de São Paulo. Rev. Eletr. Farm. 12(4): 24-31, 2015.

BORELLA, J.C.; SIMÕES, R.F.; PUGA, R.L.A; STEVANATO, M.C.B. Avaliação da estabilidade e da atividade enzimática de soluções de papaína utilizadas no desbridamento e cicatrização de feridas. Infarma. 28(3):179-184, 2016.

BORGHETTI, G.S.; KNORST, M.T. Desenvolvimento e avaliação da estabilidade física de loções O/A contendo filtros solares. Rev. Bras. Ci. Farm. 42(4):531-537, 2006.

BOU-CHACRA, N.A.; OHARA, M.T. Validação de método para avaliação da qualidade sanitária de preparação cosmética de base lipófila. Rev. Bras. Ci. Farm. 39(2):185-194, 2003.

BRASIL. Ministério da Saúde. Agência Nacional de Vigilância Sanitária. Farmacopeia Brasileira. 5a . ed. volume I. Brasília DF, 2010.

BONTORIM, G. Estudo de estabilidade de emulsão cosmética utilizando reologia e técnicas convencionais de análise. 2009. Curitiba. 74p. Dissertação (Mestrado Profissional em Química), Universidade Federal do Paraná. Curitiba.

CORRÊA, N.M.; CAMARGO JR, F.B.; IGNÁCIO, R.F.; LEONARDI, G.R. Avaliação do comportamento reológico de diferentes géis hidrofílicos. Rev. Bras. Ci. Farm. 41(1):73-78, 2005.

DUARTE, L.S.G. Desenvolvimento e estudo de estabilidade de preparações com papaína para debridamento de feridas. 2016. Niterói. 90p. Dissertação (Mestrado em Ciências Aplicadas a Produtos para Saúde), Universidade Federal Fluminense. Niterói.

FERREIRA, A.M.; OLIVEIRA, K.A.; VIEIRA, L.C.; ROL, J.L. Revisão de estudos clínicos de enfermagem: utilização de papaína para o tratamento de feridas. Rev. Enferm. UERJ. 13(3):382-389, 2005. 
FERREIRA, A.M.; WATANABE, E., NASCIMENTO, A.P.; ANDRADE, D.; ITO, I.Y. Atividade antibacteriana in vitro de géis com diferentes concentrações de papaína. Rev. Eletr. Enferm. 10(4):1035-1040, 2008.

FOOD AND DRUG ADMINISTRATION (FDA). Department of Health and Human Services. Topical drug products containing papain; enforcement action dates. Federal Register. 73(185):54831-54834, 2008.

FRIEDRICH, M.; PRIMO, F.T.; FUNCK, J.A.B.; LAPORTA, L.V.; ALVES, M.P.; BITTENCOURT, C.F.; ESCARRONE, A.L.V. Avaliação da estabilidade físico-química de creme não iônico inscrito no formulário nacional. Lat. Am. J. Pharm. 26(4):558-62, 2007. GURUNGA, S.; SKALKO-BASNET, N. Wound healing properties of Carica papaya latex: In vivo evaluation in mice burn model. J. Ethnopharmacol. 121(1):338-341, 2009.

ISAAC, V.L.B.; CEFALI, L.C.; CHIARI, B.G.; OLIVEIRA, C.C.L.G.; SALGADO, H.R.N.; CORRÊA, M.A. Protocolo para ensaios físico-químicos de estabilidade de fitocosméticos. Rev. Ci. Farm. Básica Apl. 29(1):81-96, 2008.

KNORST, M.T. Desenvolvimento tecnológico de forma farmacêutica plástica contendo extrato concentrado de Achyrocline satureioides (Lam.) DC. Compositae - Marcela. 1991. Porto Alegre. Dissertação (Mestrado em Ciências Farmacêuticas). Universidade Federal do Rio Grande do Sul. Porto Alegre.

LEITE, A.P.; OLIVEIRA, B.G.R.B.; SOARES, M.F.; BARROCAS, D.L.R. Uso e efetividade no processo de cicatrização de feridas: uma revisão sistemática. Rev. Gaúcha Enferm. 33(3):198-207, 2012.

LOPES, P.S.; RUAS, G.W.; BABY, A.R.; PINTO, C.A.S.O.; WATANABE, I.; VELASCO, M.V.R.; KANEKO, T.M. In vitro safety assessment of papain on human skin: a qualitative light and transmission electron microscopy (TEM) study. Rev. Bras. Ci. Farm. 44(1):151-156. 2008.

MAHECHA, M.M.A.; RODRIGUEZ, O.M.; CORREA. H.A.M. Estudo do processo de extração de papaína a partir do látex do fruto de mamão (Carica papaya L.) cv. Maradol. Acta Agron. 60(3): 217-223. 2011. 
MILAN, A.L.K.; MILÃO, D.; SOUTO, A.A.; CORTE, T.W.F. Estudo da hidratação da pele por emulsões cosméticas para xerose e sua estabilidade por reologia. Rev. Bras. Ci. Farm. 43(4): 649-657. 2007.

MIURA, D.Y. Desenvolvimento farmacotécnico e estudo de estabilidade de géis de papaína destinados ao tratamento de feridas. 2012. Niterói. 101p. Dissertação (Mestrado em Ciências Aplicadas a Produtos para Saúde), Universidade Federal Fluminense. Niterói.

NICOLETTI, C.D. Desenvolvimento de géis de papaína a 4,0\% (p/p) com polissorbato 80 como agente solubilizante. 2015. Niterói. 113p. Dissertação (Mestrado em Ciências Aplicadas a Produtos para Saúde), Universidade Federal Fluminense. Niterói.

PAYNE, W.G.; SALAS, E.; KO, F.; NAIDU, D.K.; DONATE, G.; WRIGHT, T.E.; ROBSON, M.C. Enzymatic debriding agents are safe in wounds with high bacterial bioburdens and stimulate healing. Eplastic. 8(1): 151-156, 2008.

PINTO, C.A.S.O. Estudo comparativo da estabilidade de formulações cosméticas contendo papaína livre e modificada. 2005. São Paulo. 128p. Dissertação (Mestrado em Fármacos e Medicamentos, Área de Produção e Controle Farmacêutico), Faculdade de Ciências Farmacêuticas da Universidade de São Paulo. São Paulo.

PINTO, C.A.S.O.; GREEN, D.; BABY, A.R.; RUAS, G.W.; KANEKO, T.M.; MARANA, S.R.; VELASCO, M.V.R. Determination of papain activity in topical dosage forms: single laboratory validation assay. Lat. Am. J. Pharm. 26(5):771-775, 2007.

PINTO, C.A.S.O.; LOPES, P.S.; SARRUF, F.D.; POLAKIEWICZ, B.; KANEKO, T.M.; BABY, A.R.; VELASCO, M.V.R. Comparative study of the stability of free and modified papain incorporated in topical formulations. Rev. Bras. Ci. Farm. 47(4):751-760, 2011.

RIBEIRO, A.P.L.; OLIVEIRA, B.G.R.B.; SOARES, M.F.; BARRETO, B.M.F.; FUTURO, D.O.; CASTILHO, S.R. Efetividade dos géis de papaína a 2\% e 4\% na cicatrização de úlceras venosas. Rev. Esc. Enferm. USP. 49(3):395-402, 2015.

RODRIGUES, A.L.S.; OLIVEIRA, B.G.R.B.; FUTURO, D.O.; SECOLI, S.R. Efetividade do 
gel de papaína no tratamento de úlceras venosas: ensaio clínico randomizado. Rev. LatinoAm. Enferm. 23(3):1-8, 2015.

SILVA, J.A.; APOLINÁRIO, A.C.; SOUZA, M.S.R.; DAMASCENO, B.P.G.L.; MEDEIROS, A.C.D. Administração cutânea de fármacos: desafios e estratégias para o desenvolvimento de formulações transdérmicas. Rev. Ci. Farm. Básica Apl. 31(3):125-131, 2010.

ASSOCIAÇÃO BRASILEIRA DE ENFERMAGEM EM DERMATOLOGIA (SOBENDE).

Recomendações sobre o uso terapêutico da papaína. 2008. Disponível em: < sobende.org.br/pdf/pronunciamento.pdf> Acesso em 07/08/2017.

SOUZA, M.C.A.; FRANCO, R.O.M.; OLIVEIRA, P.S.C.; SOUZA, E.R.P. Úlcera crônica tratada com gel de papaína $10 \%$ na estratégia saúde da família: relato de experiência. Rev. Bras. Med. Fam. Comunidade. 12(39):1-8, 2017.

STARLEY, I.F.; MOHAMMED, P.; SCHNEIDER, G.; BICKLER, S.W. The treatment of paediatric burns using topical papaya. Burns. 25(7):636-639, 1999.

VIANA, O.S.; BENIGNO JÚNIOR, J.; SILVA, R.M.F.; MEDEIROS, F.P.M.; GRANGEIRO JÚNIOR, S.; ALBUQUERQUE, M.M.; ROLIM NETO, P.J. Desenvolvimento de formulações e tecnologia de obtenção de comprimidos revestidos de efavirenz - terapia anti-HIV. Rev. Bras. Ci. Farm. 42(4):505-511, 2006.

ZANIN, S.M.W.; MIGUEL, M.D.; CHIMELLI, M.; DALMAZ, A.C. Parâmetros físicos no estudo da estabilidade das emulsões. Visão Acad. 2(2):47-58, 2001. 